\title{
Evaluation of the basic surface roughness of an ISO-certified and non-ISO-certified slot bracket with an atomic force microscope
}

\author{
Chrisni Oktavia Jusup ${ }^{1 *}$, Eky Setiawan Soeria Soemantri ${ }^{2}$, Endah Mardiati ${ }^{2}$, Ida Ayu \\ Evangelina ${ }^{2}$
}

'Department Of Orthodontics, Faculty of Dentistry YARSI University, Indonesia

2Department of Orthodontics, Faculty of Dentistry Universitas Padjadjaran, Indonesia

\begin{abstract}
Introduction: The base surface roughness of slot bracket can affect friction in tooth movement. There are ISO-certified and non-ISO-certified stainless steel brackets on the market. Thus orthodontists must be careful in choosing the right bracket. This study was aimed to evaluate the differences of the surface roughness of ISO-certified and non-ISO-certified Roth 0.022 inch stainless steel bracket with the parameter of $\mathrm{S}$ a (average roughness). Methods: This research was a laboratory observational. Samples were taken randomly as many as 32 brackets divided into two groups, each consisted of two bracket brands. Surface roughness measurements were performed using an atomic force microscope (AFM), then the data were analysed by ANOVA test ( $\mathrm{p} \& \mathrm{tt} ; 0.05$ ) and Post-Hoc analysis. Results: The ISO-certified bracket has an $S$ a value smaller than the non-ISO-certified bracket. There was a significant difference in the surface roughness of the ISO-certified and non-ISO-certified slot bracket base ( $\mathrm{p} \& \mathrm{tt}$; 0.05 ). Conclusion: The ISOcertified bracket has a smoother base surface than the non-ISO-certified bracket base.
\end{abstract}

Keywords: Surface roughness, stainless steel slot bracket, atomic force microscope

P-ISSN 1979-0201, e-ISSN 2549-6212; Available from: http://jurnal.unpad.ac.id/pjd/article/view/17956

DOI: $10.24198 / \mathrm{pjd}$. vol30no3.17956

Submission: Jul 24, 2018; Accepted: Sep 7, 2019; Published online: Jul 31, 2019

\section{INTRODUCTION}

The fixed orthodontic appliance has three essential components, namely brackets, wire arcs and accessories. The interaction of these three components determines the way the orthodontic device functions. Tooth movement in orthodontic treatment is influenced by biological and mechanical factors. ${ }^{1}$ Mechanical factors in tooth movement occur because of interactions between the bracket and the arc of the wire during tooth movement. Fixed orthodontic treatment can cause sliding movements between the bracket and the wire arc, resulting in friction resistance. An important consideration is needed in designing two contact surfaces, namely the bracket and the wire arc. ${ }^{2}$ The portion of the bracket that interacts with the wire is the bracket slot. The resulting friction force is influenced by surface conditions, the presence or absence of chemical reactions, modification of lubricant application and so on. The state of the bracket slot surface in the 
form of surface roughness affects the amount of frictional force that occurs, although the surface looks smooth, but still has a surface irregularity (asperitis). ${ }^{2,3}$ Stainless steel is the metal alloy that is most widely used in orthodontic fields such as brackets and wire arcs.

The type of stainless steel in question is austenitic stainless steel types 18-8 with a content of $18 \%$ chromium and $8 \%$ nickel. Austenitic stainless steel was chosen because of the large ductility that makes it uneasily broken, easily welded, low sensitivity, and is easily formed. ${ }^{4}$

Previous studies, which evaluated the surface roughness of the base slots of McLaughlin Bennett and Trevisi (MBT) prescription stainless steel bracket slots with a 0.022 -inch slot size, showed that there were variations in the bottom surface roughness of the bracket slot in several brands.

Evaluations were carried out using a scanning electron microscope (SEM) and a 3D non-contact surface profilometer machine. 2 Research on the Roth bracket shows that there is irregularity on the bottom surface of the slot, and after a sliding test, the surface conditions are getting rough due to scratches on the sliding movement. ${ }^{5}$ Other studies have shown that metal brackets show a high value of resistance to sliding compared to self-ligating brackets, although the relationship between the roughness of the bottom surface of the bracket slots and the resistance of sliding motion is still unclear. ${ }^{6}$ The surface roughness of the bracket also influences the level of corrosion, as in the study of Dolci et al. ${ }^{7}$, which states that surface homogeneity in orthodontic components is one of the factors to prevent corrosion. The underlying surface roughness of the varying bracket slots shows the difference in surface roughness standards owned by each of the brackets manufacturers. Agarwal et al. ${ }^{2}$ found that the brackets with four well-known brands each had different surface roughness even though all of the brackets were ISO (International Organization for Standarization) certifications.

The development of orthodontic treatment now causes many brands of brackets from various factories on the market so orthodontists must carefully choose brackets from factories with ISO certificates. Brackets that do not have ISO certificates but have other certifications such as
CE (Conformité Européene) and FDA (Food and Drug Administration) are also widely circulating in the market. Based on the background above, this study was aimed to evaluate the differences of the surface roughness of ISO-certified and non-ISOcertified Roth 0.022 inch stainless steel bracket with the parameter of $\mathrm{S}$ a (average roughness).

\section{METHODS}

This observational laboratory study used a 0.022 inch Roth slot stainless steel bracket from two brands on the market that were randomly selected, with ISO certificate and without ISO certified. The chosen bracket slot was 0.022 inch size according to recommendations from McLaughlin, Bennet and Trevisi $^{2}$ because it has the advantage of being easy to insert wire, less friction at the start of alignment and can provide higher rigidity during the retraction process, and also this 0.022 inch size slot used by orthodontic practitioners, and facilitates the research process because wing bracket cuts will be made. $70 \%$ alcohol to clean the bracket.

The study was divided into two stages: the bracket preparation stage and the bracket testing stage. Brackets that have been chosen are 8 brackets of each brand (a total of 32 brackets) with the wing cut using a micromotor and diamond bur with the aid of a magnifying glass with a magnification of $10 x$ carefully and under running water to prevent it from getting hot. The base of the bracket slot must not be hit by a bur.

The bracket slot wall must be cut parallel to or lower than the bottom of the bracket slot so that the atomic force microscope (AFM) probe can contact and move along the scanning area. The bracket was then cleaned using $70 \%$ alcohol and an ultrasonic cleaner for 10 minutes. The base of the bracket with cut wing was then examined using an optical microscope at 200x magnification to see whether there was damage to the bottom of the bracket slot. A suitable and clean bracket after being cut was then analysed using an AFM tool to know the surface topography and measure the surface roughness of the bottom of the bracket slot, as shown in Figure 1.

Each bracket sample was taken three images then select the picture with the best conditions and represents the surface conditions tested. 
The surface roughness parameter analysed was $\mathrm{S}$ a (arithmetic mean height / average roughness) because this parameter is the most commonly used, the measurement was simple and generally described the surface roughness. The data obtained were analysed by Analysis of Variance (ANOVA) test with two groups analysis using post hoc analysis ( $p \& \mathrm{lt} ; 0.05$ ).

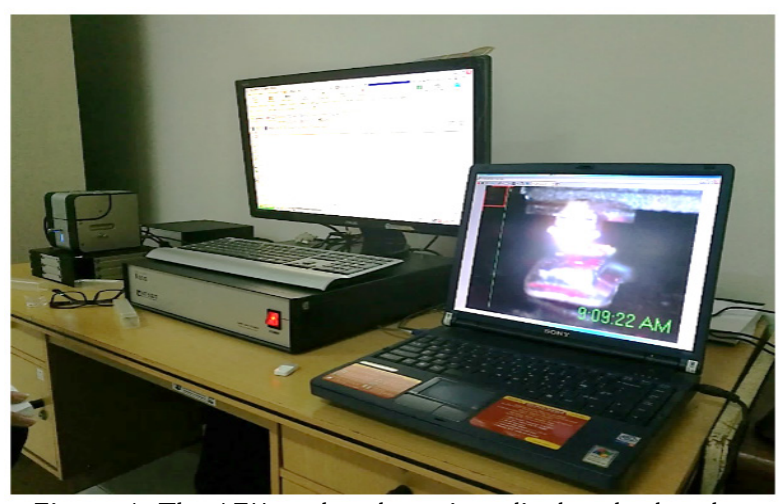

Figure 1. The AFM tool and monitor display the bracket being scanned

(Nano Devices Research Lab, Mochtar Riady Plaza Quantum Building, Faculty of Engineering University of Indonesia)

\section{RESULTS}

The bottom surface roughness test results of the 0.022 -inch Roth stainless steel bracket slots of the four brands tested are presented in table 1. Table 1 shows that the smallest mean Sa was owned by the brand $B$ bracket, followed by brand $A, D$, and $C$ consecutively. The small size of brand $B$ bracket shows that the brand $B$ bracket has the smoothest bottom surface of the slot (average Sa: 39,099 $\mathrm{nm}$ ). The mean value of the $\mathrm{C}$ brand bracket is the largest, which means that the $\mathrm{C}$ brand bracket has the roughest bottom surface of the slot (Sa mean: $128.054 \mathrm{~nm})$.

Table 1. Mean of the bracket slots of four brands surface roughness $(\mathrm{nm})$

\begin{tabular}{cccc}
\hline Brand & N & Mean & Std. Dev \\
\hline A & 8 & 64.435 & 6.384 \\
B & 8 & 39.099 & 7.127 \\
C & 8 & 128.054 & 17.484 \\
D & 8 & 98.189 & 6.300 \\
\hline
\end{tabular}

Statistical analysis using ANOVA that compares the significance of the roughness of the bottom surface of the bracket slots between the
ISO certified and non-certified bracket groups can be seen in Table 2, which shows that there was a significant difference in the surface roughness of the bracket base of ISO certified (brands A and B) and non-ISO certified (brands $C$ and $D)(p<0.05)$. The surface of the ISO-certified bracket base slot (mean $\mathrm{Sa}=51.767 \mathrm{~nm}$ ) was smaller than the nonISO-certified bracket (mean Sa $=113.122 \mathrm{~nm}$ ), which means that the bottom surface of the ISOcertified bracket slot was better than the non-ISO bracket base.

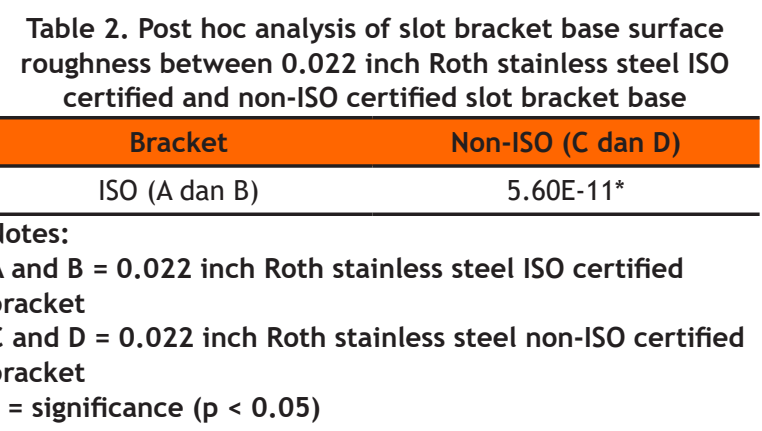

Table 3 shows that there was a significant difference in the surface roughness of the slot bracket base in the ISO certified bracket group between brand $A$ and $B(p<0.05)$. The surface roughness of the slot bracket base brand $B$ (mean $\mathrm{Sa}=39.099 \mathrm{~nm}$ ) was smaller than brand $\mathrm{A}$ (mean Sa $=64.435 \mathrm{~nm}$ ), which means the surface roughness of the slot bracket brand B was better than brand A.

Table 3. Post hoc analysis of slot bracket base surface roughness between 0.022 inch Roth stainless steel ISO certified slot bracket base brand A and brand B

\begin{tabular}{cc}
\multicolumn{2}{c}{ certified slot bracket base brand A and brand B } \\
\hline Bracket & A \\
\hline B & $2.92 \mathrm{E}-06^{*}$ \\
\hline
\end{tabular}

Notes:

$A$ and $B=0.022$ inch Roth stainless steel ISO certified bracket

* = significance $(p<0.05)$

Table 4 shows that there was a significant difference in the slot bracket base surface roughness in the non-ISO certified group between brand $C$ and $D(p<0.05)$. The surface roughness of brand $D$ slot bracket base (mean Sa $=98.189 \mathrm{~nm}$ ) was lower than brand C (mean Sa $=128.054 \mathrm{~nm}$ ), which means the surface roughness of slot bracket base brand $D$ was better than brand $C$.

Table 5 shows that the surface roughness of the slot bracket base of all brands tested showed 
significant differences $(p<0.05)$. The roughness of slot bracket base brand B was the lowest, and brand $C$ was the highest, which means that

Table 4. Post hoc analysis of slot bracket base surface roughness between 0.022 inch Roth stainless steel non-ISO certified slot bracket base brand C and brand D

\begin{tabular}{cc}
\hline Bracket & $C$ \\
\hline$D$ & $0.0005^{*}$ \\
\hline
\end{tabular}

Notes :

$C$ and $D=0.022$ inch Roth stainless steel non-ISO certified bracket

* = significance $(p<0.05$

The surface roughness obtained from scanning using an AFM tool showed the varied surface topography of the slot bracket base in each bracket brand. The surface images can be seen as a two-dimensional and three-dimensional image. Figure 2 was following the description of Table 2, Table 3, Table 4, and Table 5, which shows that the surface roughness of slot bracket base brand $B$ was the best, as seen from the topographic picture of slot bracket base brand $B$ had the best surface roughness, and slot bracket base brand $C$ had the most inferior surface.

Table 5. Post hoc analysis of slot bracket base surface roughness between 0.022 inch Roth stainless steel of all

\begin{tabular}{lccc} 
& \multicolumn{3}{c}{ brands } \\
& \multicolumn{3}{c}{ Non-ISO bracket } \\
\cline { 2 - 4 } & C & D \\
\cline { 2 - 4 } ISO Bracket & A & $1.42 \mathrm{E}-07^{*}$ & $4.28 \mathrm{E}-08^{*}$ \\
& B & $2.41 \mathrm{E}-09^{*}$ & $6.17 \mathrm{E}-11^{*}$ \\
\hline
\end{tabular}

\section{Notes:}

$A$ and $B=0.022$ inch Roth stainless steel ISO certified bracket

$C$ and $D=0.022$ inch Roth stainless steel non-ISO certified bracket

* = significance $(p<0.05)$

\section{the AFM scan.}

The surface topography of slot bracket base brand $\mathrm{A}$ bracket slot looked rougher than brand $\mathrm{B}$ but still better than brand $C$ and $D$. The surface topography of slot bracket base brand $\mathrm{C}$ looked the roughest compared to the other four bracket brands. Three-dimensional surface topography also shows variations in the four bracket brands tested, as shown in Figure 3.

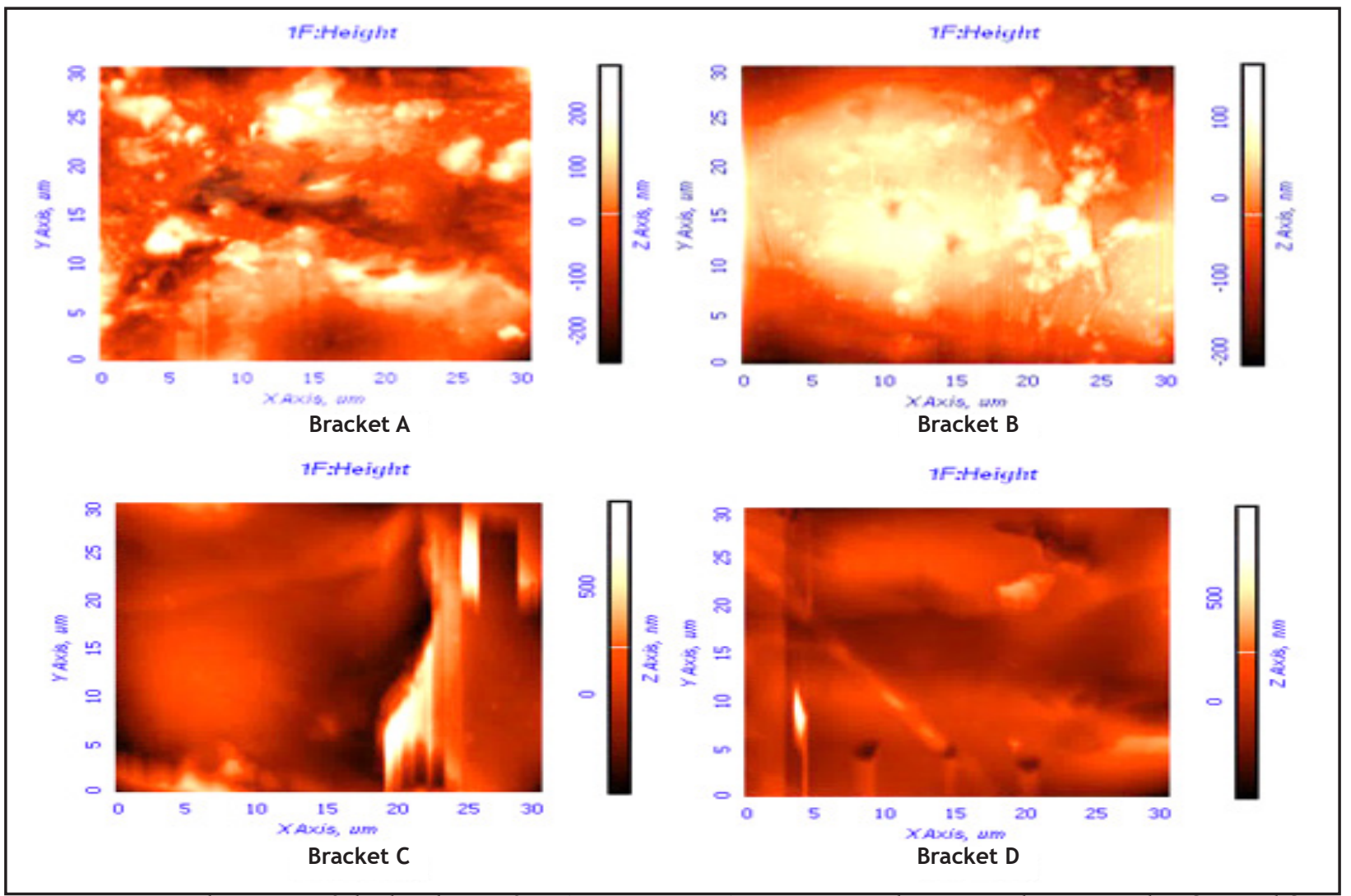

Figure 2. Topographic image of slot bracket surface $(30 \mu \mathrm{m} \times 30 \mu \mathrm{m})$ AFM scan results; A. Brand A; B. Brand B; C. Brand C; D. Brand D 


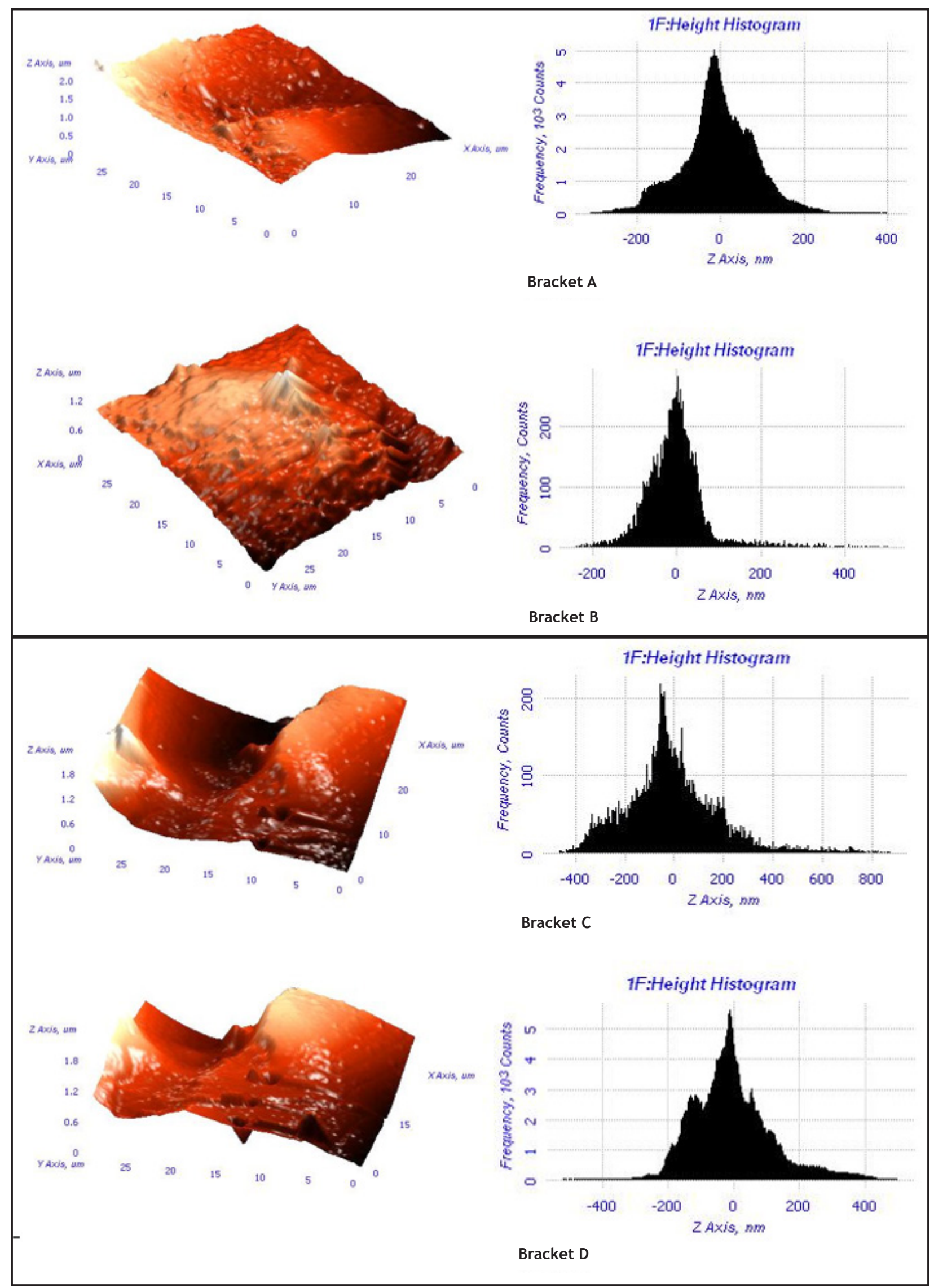

Figure 3. Three-dimensional topographic image of slot bracket surface brand A, B, C, and D from AFM scan results 


\section{DISCUSSION}

Previous studies evaluating the surface roughness of the stainless steel slot bracket base showed that there were variations in the surface roughness of the slot bracket base in several brands. ${ }^{2,7}$ This study also showed a significant difference in the surface roughness of the slot bracket base between brand $A$ and brand $B$, even though the two brands have an ISO certificate such as research by Agarwal et al. $^{2}$

The surface roughness of stainless steel slot bracket base brand A was better than brand B. The ISO certified bracket group (bracket brand $A$ and brand $B$ ) also have a significant difference compared to the non-ISO certified brackets (brand C and brand $D$ ), where the surface roughness of non-ISO certified stainless steel slot bracket was higher than the ISO-certified bracket, which means the surface roughness of ISO-certified stainless steel slot bracket base was better than the nonISO-certified.

The surface roughness of stainless steel slot bracket base is critical because it will determine the contact area, corrosion resistance, and biocompatibility ability because from research conducted by Lin8 stated that the surface roughness of the small stainless steel bracket has better corrosion resistance. Surface roughness can affect the amount of friction that occurs during orthodontic treatment, although the influence of the surface roughness of the wire arc also plays a role. ${ }^{9}$

Choosing a bracket with a good surface roughness is very important, but the process of making a bracket by the factory is not always perfect because there are still grooves and marks on the surface of the bracket slot. ${ }^{1}$ Standardisation by the International Organization for Standardization (ISO) is crucial as a guide for manufacturing brackets by manufacturers. The ISO standard for orthodontic brackets and tubes is ISO 27020: 2010 which explains the method of comparison of functions, testing methods, and packaging and labelling information. ${ }^{10}$

This research shows that although a bracket brand has an ISO certificate, there are still differences in the surface roughness value, and this also occurs in non-ISO certified brackets. The results of this study also showed that the non-ISO certified bracket had a higher surface roughness than the ISO certified bracket.

The surface roughness of stainless steel slot bracket base brand $B$ was lower than brand $A$; this condition indicated that surface roughness of stainless steel slot bracket base brand $B$ was better than brand $A$. The results of this study was consistent with the research of Lee et al. ${ }^{11}$

Lee stated that the ISO-certified bracket had different slot surface roughness. The results of the measurement of the surface roughness of stainless steel slot bracket base vary in the study related to the composition of the stainless steel metal used by the factory to make the bracket. But not all factories explain in detail what type of stainless steel is used.

The type of stainless steel commonly used as a bracket is type 304, 304L, 316 and $17-4 \mathrm{PH}$. 304L stainless steel contains $18-20 \%$ chromium, $8-10 \%$ nickel, less manganese and silicon and less than $0.03 \%$ carbon. The composition of stainless steel bracket sometimes uses 316 type which contains more nickel, 2-3\% molybdenum and lower carbon, while there is also a bracket made from stainless steel type 17-4 PH which has better mechanical ability and resistance to corrosion same as stainless steel type 304.

Previous research compared the composition of stainless steel metal type 304L, type 17-4 PH and super stainless steel. Super stainless steel contains high concentrations of nitrogen $(0.331 \%)$ and molybdenum $(6.77 \%)$, so it has corrosion resistance as well as titanium alloy. The results of a study by Fidalgo et al. ${ }^{13}$ study stated that the super stainless steel bracket has better corrosion resistance and biocompatibility than standard stainless steel, this is because the passive film is more stable so it is not easy to release nickel. ${ }^{12}$

Stainless steel has the smallest surface roughness compared to $\mathrm{NiTi}, \mathrm{TMA}$ and superelastic NiTi wire.13,14,15 The ISO certified bracket has a stainless steel composition that complies with the provisions of the American Iron and Steel Institute (AISI), but the bracket is not ISO certified not yet known whether following the requirements of AISI or not.

The surface roughness of stainless steel ISO certified slot bracket base (mean Sa $=51.767$ $\mathrm{nm})$ was lower than the non-ISO certified bracket $($ mean $\mathrm{Sa}=113.122 \mathrm{~nm})$, which means that the 
surface roughness of stainless steel ISO certified slot bracket base was better. There was a significant difference in the surface roughness of stainless steel slot bracket base brand $A$ and $B(p$ $<0.05$ ). Research conducted by Lee et al. ${ }^{11}$ on an ISO certified conventional stainless steel bracket showed a surface roughness of $52.07 \mathrm{~nm}$.

This value was similar to the value obtained by the author in this study. The surface roughness value of slot bracket brand $\mathrm{B}$ (mean $\mathrm{Sa}=39.099$ $\mathrm{nm}$ ) was smaller than brand $\mathrm{A}$ (mean $\mathrm{Sa}=64.435$ $\mathrm{nm}$ ), which means that surface roughness of stainless steel slot bracket base brand $B$ was better. Agarwal ${ }^{2}$ researched the same bracket brand (brand $B$ ), which resulted in $0.74 \mu \mathrm{m}$, higher than the results obtained by this study due to differences in the tools used.

This study used AFM while Agarwal used a Three-dimensional (3D) non-contact optical surface profilometer machine (Taylor Hobson, England, available at Bangalore, India). Agarwal's research results stated that the surface roughness of the slot brand B bracket was better compared to the bracket brand A (Sa $2.80 \mu \mathrm{m})$. The results of the study also supported the results of this study. There was a significant difference in the surface roughness of stainless steel slot bracket base brand $C$ and $D(p<0.05)$. The surface roughness of stainless steel slot bracket base brand $D$ (mean Sa $=98.189 \mathrm{~nm}$ ) was lower than brand C (mean Sa = $128.054 \mathrm{~nm}$ ), which means that surface roughness of stainless steel slot bracket base brand $D$ was better.

Our study used this bracket brand, mostly because brand $C$ and $D$ are brands with no ISO certificates. The smoothest slot bracket base surface was the brand $B$, and the roughest was the brand $C$. Lee et $\mathrm{al}^{11}$ stated in their research that the brand $B$ bracket had the smoothest slot base surface compared to other brackets at $52.07 \mathrm{~nm}$.

The surface roughness of stainless steel slot bracket base varies, even though it already has an ISO standard certificate. Our study had a disadvantage that it is difficult to remove the wing bracket. The wing bracket must be removed so that it can be scanned using AFM tools. The removal of the wing bracket was still done manually, so it is likely to affect the basic conditions of the bracket slot. A more precise wing removal method needs to be found for better research results.

Another shortcoming was that no studies conducted using non-ISO-certified brackets so that further research needs to be done on the surface roughness of non-ISO-certified stainless steel slot bracket base with more research samples.

\section{CONCLUSION}

The ISO-certified bracket has a smoother base surface than the non-ISO-certified bracket base. The ISO certificate also determines the quality of the bracket used by the orthodontist.

\section{REFFERENCES}

1. Mendes Bde A, Neto Ferreira RA, Pithon MM, Horta MC, Oliveira DD. Physical and chemical properties of orthodontic bracket after 12 and 24 months : in situ study. J Appl Oral Sci. 2014; 22(3): 194-203. DOI: 10.1590/1678775720130528

2. Agarwal CO, Vakil KK, Mahamuni A, Tekale PD, Gayake PV, Vakil JK. Evaluation of surface roughness of the bracket slot floor - a 3D perspective study. Prog Orthod. 2016; 17: 3. DOI: $10.1186 / \mathrm{s} 40510-016-0116-2$

3. Proffit W, Fields H. Contemporary Orthodontics. $5^{\text {th }}$ ed. London: Elsevier Health Science; 2013. p.329-30.

4. Anusavice KJ. Phillip's science of dental material. $12^{\text {th }}$ ed. St. Louis: Saunders-Elsevier; 2003. p. 406-7.

5. Choi SH, Kang DY, Hwang CJ. Surface roughness of three of modern plastic bracket slot floor and frictional resistance. Angle Orthod. 2014; 84(1): 177-83. DOI: 10.2319/030313179.1

6. Vale F, Malo L, Caramelo F, Ramos J, Cavaleiro J. Dynamic behavior and surface characteristics of conventional and self-ligating brackets. Rev Portug Estomatol Med Dentár Cirurgia Maxilofac. 2016; 57(1): 1-8. DOI: 10.1016/j. rpemd.2015.12.003

7. Dolci GS, Spohr AM, Zimmer ER, Marchioro EM. Assesment of the dimensions and surface characteristic of orthodontic wire 
and bracket slots. Dental Press J Orthod. 2013; 18(2): 69-75. DOI: 10.1590/S217694512013000200016

8. Lin $M C$, Lin SC, Lee TH, Huang HH. Surface Analysis and Corrosion Resistance of Different Stainless Steel Orthodontic Brackets in Artificial Saliva. Angle Orthod. 2006; 76(2): 322-329. DOI: 10.1043/0003-3219(2006)076[0322:SAAC RO]2.0.C

9. Nanjundan K, Vimala G. Evaluation of frictional resistance and surface characteristics after immersion of orthodontic brackets and wire in different chemical solutions: A comparative in vitrostudy. Indian J Dent Res. 2016; 27(5): 51320. DOI: $10.4103 / 0970-9290.195641$

10. International Organization for Standardization [homepage on internet]. Geneva: International Organization for Standardization. 2017. About ISO [cited 2018]; [about 4 screens]. Available from: https://www.iso.org/about$\underline{\text { us.html }}$
11. Lee GJ, Park KH, Park YG, Park HK. A quantitative AFM analysis of nano-scale surface roughness in various orthodontic brackets. Micron. 2010; 41(7): 775-82. DOI: 10.1016/j.micron.2010.05.013

12. Oh KT, Choo SU, Kim KM, Kim KN. A stainless steel bracket for orthodontic application. Eur J Orthod. 2005; 27(3): 237-44. DOI: $10.1093 /$ ejo/cji005

13. Fidalgo TK, Pithon MM, Maciel JV, Bolognese $A M$. Friction between different wire bracket combinations in artificial saliva - an in vitro evaluation. J Appl Oral Sci. 2011; 19(1): 57-62. DOI: $10.1590 / \mathrm{s} 1678-$ $\underline{77572011000100012}$

14. Hsu JT, Yu JH, Wu LC, Chang YY, Huang HH, Huang HL. Surface Roughness and Topography of Four Commonly Used Types of Orthodontic Archwire. J Med Biol Eng. 2011; 31(5): 367-70. DOI: $10.5405 / \mathrm{jmbe} .700$

15. Yousif AA, El-Karim UM. Microscopic study of surface roughness of four orthodontics arch wires. Tanta Dent J. 2016; 13(4): 199-207. DOI: $\underline{10.4103 / 1687-8574.195714}$ 